\title{
Implementation of knowledge management in organizations
}

\author{
Katrin Winkler · Heinz Mandl
}

Received: 30 December 2006/Accepted: 10 January 2007/Published online: 17 March 2007

(C) Springer Science+Business Media, LLC 2007

\begin{abstract}
In the context of learning implementation of new ideas e.g. knowledge management in organizations often is neglected. Concerning knowledge management measures we demonstrate its implementation in organizations. A theoretical framework was developed showing the necessary basic conditions for implementing knowledge management. Subsequently we integrate the framework into a process model illustrated by a case study.
\end{abstract}

Keywords Implementation - Knowledge management - Change analysis · Management concept $\cdot$ Acceptance concept

In the context of learning implementation of new ideas e.g., knowledge management in organizations often is neglected. Knowledge management describes the conscious and systematic handling of the resource of knowledge and its targeted application within an organization (Reinmann-Rothmeier, Mandl, Erlach, \& Neubauer, 2001). In the light of knowledge management measures we will demonstrate its implementation in organizations. We first work out a theoretical framework showing the necessary basic conditions for implementing knowledge management. Subsequently we integrate the framework into a process model that will then be illustrated by a case study. At first we will present implementation-relevant psychological aspects.

\section{Implementation-relevant psychological aspects}

The individual is at the center of all knowledge management initiatives (ReinmannRothmeier \& Mandl, 1999). This statement is important both for the creation of knowledge management instruments and also for the implementation of knowledge management

K. Winkler · H. Mandl $(\bowtie)$

Department Psychologie, Ludwig Maximilian University Munich, Leopoldstrasse 13,

80802 Munich, Germany

e-mail: heinz.mandl@psy.lmu.de 
measures due to the fact that the introduction of any new innovation is reliant on employee support (Tarlatt, 2001). According to Tarlatt (2001), the decisive psychological aspects are perception, reactance, opposition, and conflict. Each of these will be briefly described in this section.

Perception. The success of an implementation is dependent on the perception of the situation and circumstances. Individuals will perceive the benefits of implementing and innovation differently, due to the fact that they will interpret the perceived information on the basis of their own previous experiences and motivational aspects (see Gerstenmaier \& Mandl, 1995). Therefore, the evaluation of how essential and meaningful the innovation is, is rather subjective in nature. For the implementation process, this means that those involved and affected understand the benefits of the innovation. Their perception can be influenced. For example, incentives may boost an individual's motivation of perception (Tarlatt, 2001).

Reactance and Opposition. Opposition that results from reactance is a phenomenon that substantially contributes to the success or failure of a proposed implementation. Reactance is described as a motivational state of tension that is directed at opposing an impending or existing restriction and that focuses on maintaining or regaining behavioral leeway (Dickenberger, Gniech, \& Grabitz, 1993). Individuals aim to reduce reactance. This may occur through a behavioral change with respect to the modified situation or through cognitive restructuring. Behavioral changes may be manifested as acts of defiance, flight, or aggression (Brehm \& Brehm, 1981). In cognitive adaptation the individual is concerned with revaluating the blocked alternatives. This behavior is described as opposition. Opposition that results from reactance can lead to the substantial disturbance of an implementation, for example, by causing process delays. According to Tarlatt (2001), opposition may appear in different forms: as open or as hidden opposition. Open opposition manifests itself, for example, in comments about grievances or about situations relevant to the implementation. Hidden opposition can be implicitly recognized in the behavior of individuals or groups. Hidden opposition results in an individual when a sufficiently high level of reactance has been reached. Examples of triggers may be fear of losing one's job, uncertainty about the degree and consequences of the innovation, fear of losing autonomy, lack of willingness to learn new skills and behaviors, etc. Specific actions may impede some of these factors. Such actions could be, for example, employing communication and motivational measures during the implementation process to facilitate a smooth rollout.

Conflict. Conflicts often occur in situations in which decisions are made by more than one person. This is the case for complex implementation projects. A conflict can be viewed as a process in which one party purposely acts to thwart the efforts of a second party through a blockade (Tarlatt, 2001). The sooner that conflicts in the implementation processes are recognized and blockades removed, the more smoothly the implementation process will run. A conflict analysis can help guard against conflict-related disturbances during the implementation process. However, this is often problematic due to the fact that conflict situations often remain hidden. In such cases, it is often difficult to propose a solution for the conflict due to the fact that it has not been possible to conduct an open conflict analysis (Raimond \& Eden, 1990). In order to work purposefully to counteract conflicts, it is important to consider the possible causes of the conflict. For example, these may be heterogeneous group composition, role conflicts, exercise of power, or resource shortages (Tarlatt, 2001). The successful implementation of innovations is linked significantly to the acceptance of the affected parties (Grattson, 1996). A meaningful goal of the implementation project is therefore to prevent reactance and increase the acceptance 
of the involved parties. When planning the implementation process, it is hence particularly important to consider psychological aspects. The following framework model focuses on these aspects and can be described as an employee-oriented implementation process.

\section{A basic procedural model for implementing knowledge management}

Introducing new concepts is seldom unproblematic, as is demonstrated by the psychological aspects described in the previous section. Some exemplary problem areas, which emerge time and time again, can be understood from this perspective (see Alexander, 1985). In many cases, the purpose of introducing a new concept, such as knowledge management, is unclear, too abstract or too generally formulated. Consequently, the project is often doomed to failure from the outset due to the fact that conflicts are pre-programmed and even the clear communication of the project is impeded. It is often the case that the implementation of an innovation does not meet the actual needs of the employees. The lack of usage of many technical knowledge management platforms associated with high levels of investment is just one example of this. It is not uncommon for the parties who are actually affected by the process to be excluded from the realization process. In such cases, they are simply confronted with the innovation upon rollout. A further problem area is the lack of evaluation, especially evaluation that accompanies the process. Often the need for tailoring simply goes unrecognized. This and similar problems finally result in the fact that the new initiative remains unused and lacks employee acceptance.

When introducing knowledge management, it is highly important that knowledge management is not introduced stand alone, but rather in the context of optimizing a business process. In the stricter sense, it is not about introducing knowledge management, but about implementing concrete knowledge management instruments and measures that support and optimize a specific business process. This ensures that the innovation is relevant to the workplace and is more easily understood by employees. In this context, it becomes clear that a comprehensive procedure for a purposeful and acceptance-oriented implementation must precede the introduction of knowledge management instruments and measures. This procedure should be largely centered on the needs of the end user in order to actually contribute to the optimization of a process.

The process model proposed is based on Tarlatt (2001) and consists of three main phases. Phase 1: Change analysis; Phase 2: Realizing the Implementation; Phase 3: Monitoring the Implementation.

Phase I: change analysis

The change analysis phase, during which the implementation project is defined, is comprised of two sub-areas: Initialization and Requirements Analysis

\section{Initialization}

The sub-area of Initialization focuses on the definition of the initial implementation goals. Three steps are key to this definition: strategic planning, business case, and steering group. 
Strategic Planning. The starting point of strategic planning is developing a vision for the implementation project. Key to developing this vision is securing management support and defining initial strategic goals. From the outset, these are the aspects that determine the success or failure of the implementation of knowledge management initiatives (see Teschke, Zimmer, Diefenbruch, \& Hädrich, 2003).

In many cases when defining implementation goals, it makes sense to differentiate between normative, strategic, and operative knowledge goals. According to Probst, Raub and Romhardt (2000), normative knowledge goals pertain to the level of the basic vision of corporate policy and to all aspects that are related to the organizational culture. Some examples of normative knowledge goals are the specific knowledge mission statement of the organization, the identification of critical knowledge areas, or the innovative spirit of the organization. Strategic knowledge goals are formulated for long-term measures that serve to realize the normative goals or the organizational vision. Goals at this level could be to develop core competencies, cooperation, or problem-oriented knowledge identification. Finally, operative knowledge goals are the basis for realizing the strategic program in the context of the daily activities within the organization. These include, for example, introducing expert databases, constructing a knowledge infrastructure or introducing computer-based learning programs (Probst et al., 2000). In practice there are several different methods used to define knowledge goals (Pawlowsky, 1998). For the most part, the processes used can be categorized within the domain of classical and expanded training needs analysis, such as informal discussion sessions with management, yearly further training plans, etc. A more in-depth method for defining knowledge goals is the organizational diagnosis (see Koch \& Mandl, 1999). This diagnosis is centered on the current situation within the organization. Another possibility is to develop an "as-is"' knowledge profile (Schüppel, 1996). In this profile, for example, the competencies of the organization are defined-most often in table form. Using these methods helps with the gathering of relevant information for defining implementation goals. In the sub-area of initialization, no concrete operative goals are defined. This is because to do so would require information from the sub-area of requirements analysis.

Business Case. The business case provides the implementation project with its first written framework. The business case describes the implementation problem, the vision, and the initial strategic goals for the project. In addition, performance figures and measurement categories are defined. The business case includes a detailed budget plan and an initial rough estimate of the cost-benefit relationship. This information is particularly useful to present to those responsible for the budget and for obtaining management buy-in.

Steering Group. It is necessary to define a steering group in order to prevent the diffusion of responsibilities in the project, that is, the unclear allocation of responsibilities. This group is mainly responsible for reviewing whether goals are met in terms of the project's partial goals and work packages.

\section{Requirements analysis}

Against the background of the vision and the strategic goals, it then becomes necessary to perform a concrete requirements analysis. After the initial normative definition of a knowledge goal, the analysis of requirements is necessary as a starting point for developing concrete operative goals. In the first step of the requirements analysis, the current situation within the organization is described within a requirements analysis (as-is analysis) on the basis of the vision and strategic goals. The requirements analysis must be performed in 
close coordination with the actual users in order to minimize reactance, to reduce the potential for conflict and to generate a positive attitude from the users. The principle that applies is "ensuring that those affected become participants". Possible instruments that can be used for the analysis include surveys and interviews with the involved parties. Following the analysis, the desired target state is defined, again in close cooperation with the end users. This should focus on their concrete work-related issues. The comparison of the as is analysis and the target state is then used to determine requirements. This then becomes the starting point for the concrete project decision and for the definition of operative goals.

Phase II: realizing the implementation

Following a detailed analysis of the basic situation, the second phase concentrates on the sub-area of conception. This is then followed by the sub-area of realization in which the actual implementation takes place.

\section{Conception}

The sub-area entitled conception contains the detailed work on a measures concept, project management concept, and an acceptance concept.

Measures Concept. This includes a detailed description of the individual measures to be implemented and the detailed aspects of the innovation. In addition to the procedural steps for implementation, the selection of the target group is described. The measures concept forms a starting point for project management planning.

Project Management Concept. Next, the procedures for the implementation are described in a project management concept. This includes the description of the development of the subject matter, organizational aspects, and framework conditions for the implementation phase. The concept contains classical project management aspects such as a description of work packages and a detailed schedule.

Acceptance Concept. The acceptance concept is becoming increasingly important from a psychological perspective. In this concept, concrete measures for ensuring acceptance are developed. The actual usage of the measure being introduced is defined as the indicator for acceptance (Harhoff \& Küpper, 2002). Hence, acceptance is a result of motivated action. This simply means that the employees must be motivated to use the newly introduced measure. Prior experience and initial results of research indicate four levels, which can be used to create motivating circumstances and thereby ensure the acceptance of a measure (according to Tarlatt, 2001; VBM, 2000): Organization, Technology, Participation, and Qualification.

Organization. Management support is a basic requirement for facilitating acceptance (VBM, 2000). The importance of the project is communicated to employees when it becomes integrated into the overall mission of the organization. The measure can be further supported by comprehensively and continually informing employees (Tarlatt, 2001). Integrating the innovation into business processes has also proven to be a considerable success factor during the implementation process. Material and immaterial incentives as motivators may further support the process (Tarlatt, 2001).

Technology. When using technical instruments to support knowledge management measures, it is crucial to select a suitable technology that focuses on the concrete needs of employees. The technology selected must also meet the requirements for user-friendliness. 
Participation. It is key to include employees in the process from the outset in order to ensure that their actual needs are met. Even during the planning and conception phase, employee feedback should be gathered continuously (Hinkofer \& Mandl, 2003). It is useful for this purpose to apply a continual formative evaluation. The motto here is also "ensuring that those affected become participants!".

Qualification. To ease the employee's introduction to the innovation, it is necessary to implement a qualification that accompanies the process on a technical and methodical level (Tarlatt, 2001; VBM, 2000).

The selection of methods available for creating motivational framework conditions emphasizes the significant role that acceptance plays in the introduction of innovations. Realization takes place once this preparation is complete.

\section{Realization}

The sub-area entitled realization is comprised of the aspects of piloting, formative evaluation, rollout and lessons learned.

Pilot Project. Piloting the project is key for identifying potential problem areas prior to the general rollout and for ensuring that the general acceptance of the project is not put at risk. Realization therefore begins with an initial pilot project for implementing the concept, e.g. the initial introduction of a knowledge card in a specific area. When selecting pilot group participants, it is not advisable to involve individuals who have any negativity towards the project. This is because the project group participants should emerge as the main project promoters. The "implementation" project team work to advance and promote the project. In this phase, it is also key to clarify the responsibilities for each of the individual processes.

Formative Evaluation. To identify the problem areas within the project in this phase, it is necessary to conduct a structured formative evaluation for the pilot. This will serve as a basis for the continuous improvement of the project. Both aspects of the quality and effectiveness of the measure should be incorporated. The results of the pilot project's formative evaluation form the basis for making adjustments prior to the general implementation during the rollout phase.

Rollout. The aspect of rollout includes the implementation of the project in all desired areas of the organization. The results from the formative evaluation serve as the basis for the rollout procedure. Prior to rollout, it is crucial that management send out a communication regarding the project, in order to dispel any uncertainties that participants may have.

Lessons Learned. A reflection meeting is held for the implementation team and the steering group. The purpose of this meeting is to identify problem areas that occurred during the pilot and in the preceding process and to document them in the form of a lessons learned report (Reinmann-Rothmeier et al., 2001).

Phase III: monitoring the implementation

A summative evaluation of the project is crucial for ensuring continuous process improvements and the project's adaptation to the needs of the users. To this end, a quality analysis, an effectiveness analysis, and a cost-benefit analysis are conducted.

Quality Analysis. In the quality analysis, subject matter experts evaluate the measure with respect to the relevant dimensions formulated in the Business Case. The analysis of 
these dimensions must always focus on the goals pursued by the measure. To conduct the analysis, it is necessary to develop a criteria catalog that is subsequently used by the experts to evaluate the measure. It is absolutely necessary to involve the organization's quality assurance department in this analysis.

Effectiveness Analysis. The effectiveness analysis examines the measure with respect to its effect on the target group. For this reason, the target group is directly addressed through surveys. When conducting an effectiveness analysis, it is also necessary to focus on the previously defined normative, strategic, and operative goals. The assessment of the target group's acceptance is central for considering the psychological aspects that were presented earlier.

Cost-Benefit Analysis. A cost analysis is performed on the basis of the cost calculation and the verification of whether the defined performance figures outlined in the business case were achieved. A cost-benefit analysis makes reference to further potential for improvements and may serve as a basis for the internal marketing of the innovation. Figure 1 provides an overview of the process flow model for an implementation.

The process flow described here serves as an example. Depending on the specific requirements of the organization, this process must be modified or changed. Implementing complex knowledge measures does not involve the 1:1 transfer of the process from one organization to another. Rather, such an implementation involves the adaptation of specific business-process oriented procedures to suit the requirements of those involved.

In the following section, the employee-oriented implementation processes just described will be made more concrete using a real-life example.

\section{Implementation of knowledge management in a pharmaceutical company}

In the course of introducing new products to the market, a leading pharmaceutical company recognized the need for employing knowledge management activities to improve the knowledge processes of the pharmaceutical sales representatives. Management initiated the idea for a project in this area due to the new challenges associated with product

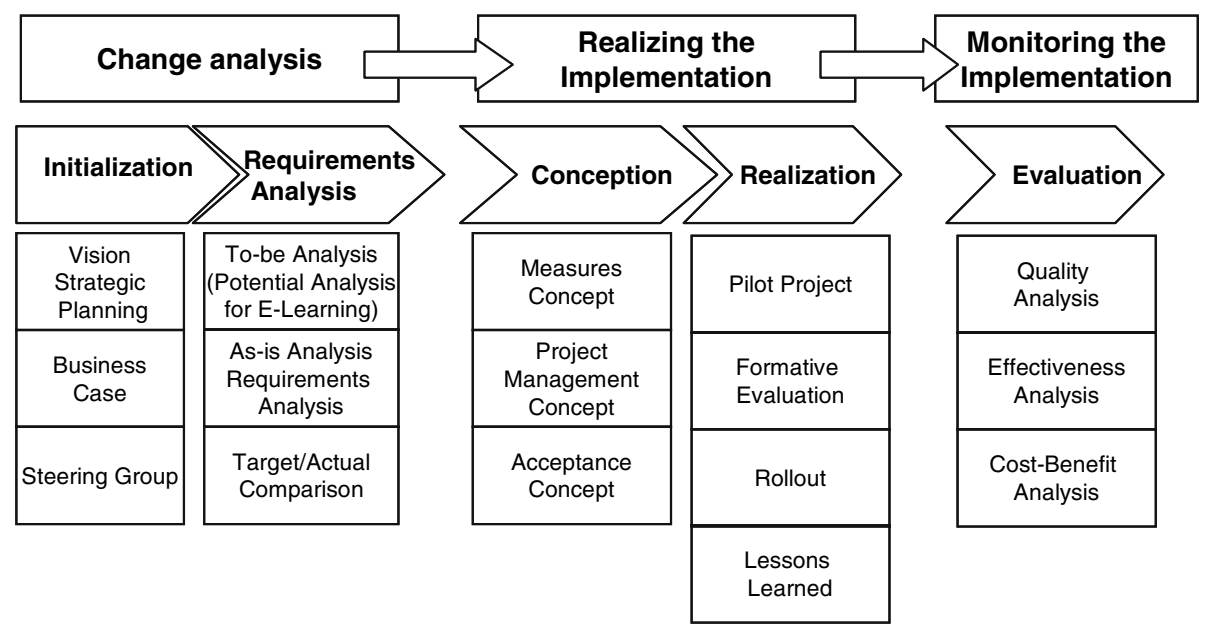

Fig. 1 Process flow for an implementation 
introduction. The company sought support from the Department of Empirical Education and Educational Psychology at the Ludwig Maximilian University Munich, who accompanied them throughout the project process.

\section{Background}

The product, market and sales know-how of the sales force contributes greatly to the success of products and therefore to the success of the company as a whole. This knowledge must be kept current through continual training. Management criticized the varying degrees of quality in the preparation of face-to-face trainings. Furthermore, they were concerned about the time required for these trainings, especially when the introduction of a new product was involved.

Phase I: change analysis

In the sub-area entitled Initialization, management conceptualized a vision to improve their competitive edge by optimizing their knowledge processes. A business case for the project was formulated and agreed in conjunction with management to clarify the project procedures and to estimate the budget. In addition, a steering group was formed to clarify the project responsibilities from the outset of the project. The actual start of the project was the Requirements Analysis, which determined the as-is status of the knowledge processes involved in the work of the pharmaceutical representatives. Another purpose of the analysis was to survey what the company required for the future. All potentially affected parties, ranging from the pharmaceutical representatives to the regional managers to the marketing, technical, and training departments to the management board were involved in this analysis.

The results of the requirements analysis indicated that the goal of the project must result in a better utilization of knowledge, concretely pointing to the improvement of the consultation sessions. Three knowledge goals were identified with respect to knowledge representation, knowledge generation, and knowledge communication. Firstly, information should be represented such that employees are able to quickly access the information. For the process of knowledge generation, the goal formulated was to facilitate the needoriented acquisition of knowledge. Furthermore, on the basis of the results of the requirements analysis, it was shown that knowledge communication should strive to improve the exchange of information and cooperation between the company's employees.

On the basis of these concrete project goals, Phase II of the project started: the phase entitled Realizing the Implementation.

Phase II: realizing the implementation

The sub-area Conception focused on fulfilling the goals stated above. There were three main emphases, which were considered in the Measures Concept.

Knowledge Representation. At the forefront of knowledge representation was the improvement in the preparation and dissemination of information about the new product, about the newest discoveries in the pharmaceutical industry and about consultation sessions. To ensure the quick dissemination of information, a technical tool in the form of a 
knowledge management platform was to be used to enable the meaningful structuring and quick recall of information. The emphasis here was on providing an informational offering, which was accessible to employees at any time, in any location.

Knowledge Generation. In order for employees to acquire the new product information on a tailored basis, the company decided to implement a blended learning scenario based on the latest findings in teaching and learning psychology.

The combination of e-learning and face-to-face training provided the basic form of the blended learning and was implemented within the company using the results of the requirements analysis. The following process was designed for this purpose (Figure 2):

Product training based on the blended learning concept consisted of three elements:

1. Online-Preparation Phase: During this phase, employees learned the basics of the new project and key aspects of product consultations sessions using a web-based training. This contained two different access methods in order to enable the flexible interaction with the learning medium: systematic and case-based access.

- Learning Path A: Systematic Access. This learning path focuses on the systematic transfer of knowledge. The contents are divided into chapters that each relate to a single module and build upon one another with respect to knowledge transfer.

- Learning Path B: Case-based Access. Learning Path B offers different consultation cases, which are structured in a problem-oriented way. Each case requires that the employees employ their knowledge to solve the case.

Employees are supported and advised by so-called e-trainers, who are specially trained for this task. The first phase concludes with an online knowledge test. Passing the test is required for participation in the face-to-face phase.

2. Face-to-face phase: Building upon the basic knowledge acquired online during Phase $\mathrm{I}$, there is more time during the face-to-face trainings to complete exercises in which the knowledge must be applied.

3. Online follow-up phase: Following the face-to-face training, the WBT serves as a permanently accessible reference resource with the advantage that it is possible to quickly access information that can be permanently kept up-to-date.

Knowledge Communication. In order to increase the exchange of information and cooperation between employees, supervised discussion forums were introduced. In these sessions, employees are able to discuss experiences and problems relating to the new
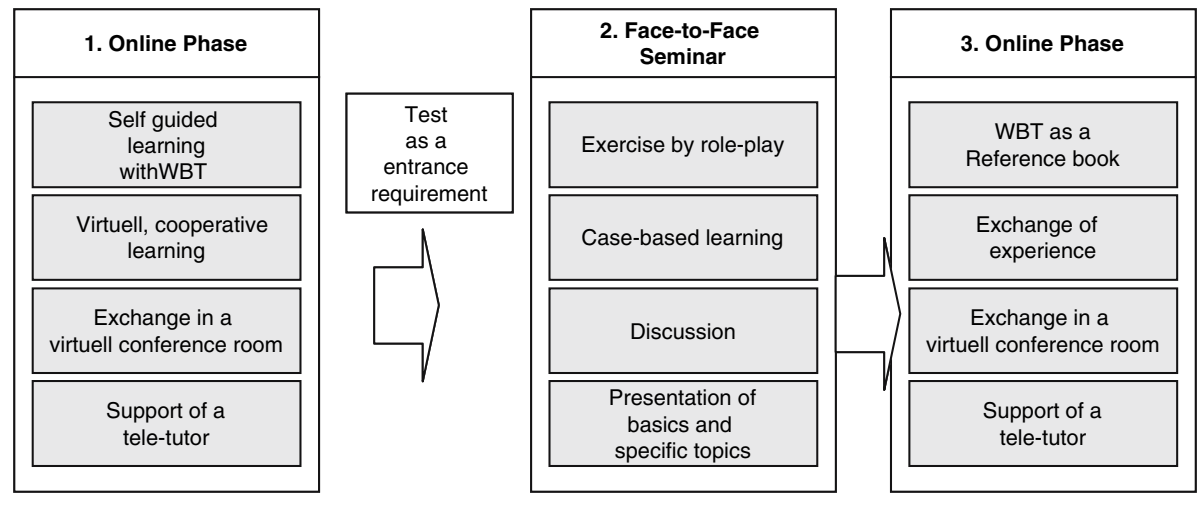

Fig. 2 Structure of the product training 
product. In addition to communicating through these discussion forums, a virtual classroom is also provided for the course-related and non course-related exchange of information.

The implementation of the measures concept requires a detailed Project Management Concept. This is necessary because several aspects must be worked on in parallel, for example, the selection of a suitable platform, the creation of the product web-based training, training for the tutors, etc.

Prior to the implementation of the project, an Acceptance Concept is presented, which contains the aspects of organization, technology, participation, and qualification, as described in the previous section.

Organization. The project was initiated by management. In this way, the basic requirement of ensuring management support was met. With respect to the organization, the project then worked to integrate the knowledge management perspective into the organization's mission statement. In addition, employees were kept informed from the beginning about project goals and status through newsletters and information sessions. A key aspect of integrating the knowledge management platform was to directly integrate it into the working processes of the participants (e.g., ordering consultation materials). The change in organizational structures was developed in close coordination with the worker's council. A certain amount of latitude was foreseen for knowledge acquisition and for working with the platform.

Technology. This aspect was of key importance since the project involved the introduction of a technology-based system. A technology-oriented requirements analysis was carried out to create a technical basis suitable for the user. A detailed didactic concept served as a basis for the selection of the technology. Following the selection of the necessary technical resources, the project ensured that all the pharmaceutical representatives were provided with the necessary equipment.

Participation. Aspects of participation were integrated into the project from the outset, for example, by involving all affected parties in the requirements analysis. In addition, the pharmaceutical representatives were also involved in the pilot introduction to ensure that the project was optimally adapted to meet their needs. Participants were constantly asked to provide their feedback on the new process.

Qualification. Aspects of qualification were also considered. The participants were given an introduction to the platform and to the new processes. In addition, e-trainers were also trained to support employees.

Following this conceptual phase and as a precursor to the actual implementation, the system was selected according to the previously defined criteria for system selection. After all system components and the web-based training were completed and adapted, the platform and the product web-based training were installed in Realization Step 1 and evaluated in a pilot phase involving 20 employees. In Realization Step 2, the system was rolled out to all employees.

Phase III: monitoring the implementation

During the pilot evaluation, a formative Quality and Effectiveness Analysis was conducted. The evaluation focused on the user-friendliness and the acceptance of the platform and web-based training. The quality of the program was constantly monitored by didactics experts and subject-matter experts. The emphasis of the summative evaluation was on the following dimensions: Acceptance, Participation, Learning Success, Integration into the 
Working Processes, Management Support, and Technology. Initial results indicated a high acceptance of the measure and also positive aspects relating to knowledge exchange and communication. Following the project, there is also a planned Cost-Benefit Analysis.

\section{Future perspectives}

As demonstrated, the implementation of knowledge management measures in organizations is a complex undertaking. Especially the importance of the human factor should not be underestimated. A successful implementation can be achieved through well thought-out, employee-oriented implementation processes. However, it is also clear, that additively summing together the various implementation success factors does not make sense. These mainly offer only abstract starting points. By using a process model, it is possible to strategically support employee-oriented implementation processes that prevent reactance and increase employee's acceptance of the innovation.

\section{References}

Alexander, D. L. (1985). Successfully implementing strategic decisions. Long Range Planning, 3, 91-97.

Brehm, S. S., \& Brehm, J. W. (1981). Psychological reactance - a theory of freedom and control. New York: Academic Press.

Dickenberger, D., Gniech, G., \& Grabitz, H.-J. (1993). Die Theorie der psychologischen Reaktanz. In D. Frey, \& M. Irle (Eds.), Theorien der Sozialpsychologie. Band 1: Kognitive Theorien (pp. 243-273). Bern: Huber.

Gerstenmaier, J., \& Mandl, H. (1995). Wissenserwerb unter konstruktivistischer Perspektive. Zeitschrift für Pädagogik, 41, 867-888.

Grattson, L. (1996). Implementing a strategic vision - Key factors for success. Long Range Planning, 3, 290-303.

Harhoff, D., \& Küpper, C. (2002). Akzeptanz von E-Learning. Eine empirische Studie in Zusammenarbeit von Cognos und dem Institut für Innovationsforschung, Technologiemanagement und Entrepreneurship. München: INNOtec.

Hinkofer, L., \& Mandl, H. (2003). Implementation von E-Learning in einem Pharmaunternehmen (Praxisbericht Nr. 28). München: Ludwig-Maximilians-Universität, Lehrstuhl für Empirische Pädagogik und Pädagogische Psychologie.

Koch, S., \& Mandl, H. (1999). Wissensmanagement - Anwendungsfelder und Instrumente für die Praxis (Forschungsbericht Nr. 103). München: Ludwig-Maximilians-Universität, Lehrstuhl für Empirische Pädagogik und Pädagogische Psychologie.

Pawlowsky, P. (1998). Wissensmanagement. Erfahrungen und Perspektiven. Wiesbaden: Gabler.

Probst, G., Raub, S., \& Romhardt, K. (2000). Wissen managen. Wie Unternehmen ihre wertvollste Ressource optimal nutzen. Wiesbaden: Gabler.

Raimond, P., \& Eden, C. (1990). Making strategy work. Long Range Planning, 5, 97-105.

Reinmann-Rothmeier, G., \& Mandl, H. (1999). Wissensmanagement: Modewort oder Element der lernenden Organisation? Personalführung, 12, 18-23.

Reinmann-Rothmeier, G., Mandl, H., Erlach, C., \& Neubauer, A. (2001). Wissensmanagement lernen. Ein Leitfaden zur Gestaltung von Workshops und zum Selbstlernen. Weinheim: Beltz.

Schüppel, J. (1996). Wissensmanagement. Wiesbaden: Gabler.

Tarlatt, A. (2001). Implementierung von Strategien im Unternehmen. Wiesbaden: Gabler.

Teschke, K., Zimmer, D., Diefenbruch, M., \& Hädrich, T. (2003). Wissensmanagement erfolgreich einführen. ExperPraxis, 35-38. Available at: http://www.experteam.de/startd/publikationen/Artikel/ Ber03_HAE.html?Branchen+Finanzdienstleister (07.03.04.).

Verband der Bayerischen Metall- und Elektroindustrie e.V. (VBM). (Hrsg.). (2000). Wissensmanagement für die Praxis. München: VBM. 